\title{
Evaluation of Porous Silica Glasses as Insect Pheromone Dispensers
}

\author{
Aline Tiboni, ${ }^{a}$ Miryan D. A. Coracini, ${ }^{a}$ Eraldo R. Lima, ${ }^{b}$ Paulo H. G. Zarbin ${ }^{a}$ and Aldo J. G. Zarbin ${ }^{*, a}$ \\ ${ }^{a}$ Departamento de Química, Universidade Federal do Paraná, CP 19081, 81531-990 Curitiba-PR, Brazil \\ ${ }^{b}$ Departamento de Biologia Animal, Universidade Federal de Viçosa, 36571-000 Viçosa-MG, Brazil
}

\begin{abstract}
Este trabalho demonstra a viabilidade da utilização de vidros porosos como materiais para armazenar e liberar feromônios de insetos, visando o controle de pragas na agricultura. Feromônios de diferentes insetos foram impregnados em vidros porosos do tipo Vycor (PVG), e o material impregnado foi caracterizado por espectroscopia de absorção no infravermelho. A determinação da taxa de liberação do feromônio em laboratório, bem como o teste prático de captura de insetos em diferentes plantações, foram subsequientemente realizados. Foram realizados testes com feromônios da Grapholita molesta (Lepidoptera: Tortricidae) e Leucoptera coffeella (Lepidoptera: Lyonetiidae), as principais pestes da maçã e café, respectivamente, em plantações brasileiras. Verificou-se que a taxa de liberação do feromônio depende do tipo de interação com as paredes dos poros do PVG. Os resultados indicaram uma boa performance do $\mathrm{PVG}$, semelhante à de septos de borracha utilizados comercialmente como liberadores. Estes resultados, somados ao fato de que o PVG não é nocivo ao meio ambiente e pode ser reutilizado em vários ciclos de impregnação e liberação, fazem destes vidros porosos candidatos em potencial para aplicação no controle de pragas na agricultura.
\end{abstract}

This work demonstrates the viability and advantages of using porous silica glass as an insect pheromone dispenser, in order to control insect population in agriculture. Pieces of so-called Porous Vycor Glass (PVG) were impregnated with pheromones of different insects (both consisting of a single compound or a mixture of compounds). Studies were conducted to characterize the impregnated-PVG and to determine the pheromone release ratio under laboratory conditions. The practical application was verified in two different plantation areas, using the PVG impregnated with pheromone from Grapholita molesta (Lepidoptera: Tortricidae) and Leucoptera coffeella (Lepidoptera: Lyonetiidae), the main pests of apple and coffee plantations in Brazil, respectively. The release rate was dependent on the interaction between the molecules of the impregnated pheromone and the surface of the PVG pores. A good performance of the porous glass was observed, similar to that of rubber septa commercially used as pheromone dispensers.

Keywords: porous glass, adsorption, pheromones, slow release, chemical ecology

\section{Introduction}

The number of insects and other species that are developing resistance to pesticides is growing steadily, forcing chemical companies to work out novel pesticide formulas. The concept of integrated pest management (IPM) was developed in response to the problems caused by the increased use of conventional pesticides. IPM combines chemical, biological, and agrotechnical approaches to achieve pest control at a reasonable cost, while minimizing damage to the environment. The first step in IPM is to perform effective monitoring through the uses of pheromones. ${ }^{1-3}$

\footnotetext{
*e-mail: aldo@quimica.ufpr.br
}

Pheromones are substances which occur in nature and are used for chemical communication between animals of the same species. The main ways by which pheromones can be exploited to control pests are monitoring, mating disruption and mass trapping. ${ }^{1-3}$ Such pheromone applications provide significant cost and environmental benefits to the farmer, the consumer, and society. Reliable pheromone lures are already in use in Brazilian orchards for monitoring the seasonal abundance of the Oriental fruit moth, Grapholita molesta (Lepidoptera: Tortricidae), the main pest in apple and other temperate fruits in Brazil. The coffee leaf miner, Leucoptera coffeella (Lepidoptera: Lyonetiidae) is the main pest of coffee plantations in Brazil, and its pheromone has been studied aiming to develop monitoring lures for this species. 
In order to be used in practical applications, pheromones need to be previously incorporated into a suitable dispensing material. Dispensers are materials with structural characteristics that enable them to adsorb the pheromone molecules, and further provide slow and controlled release of those molecules during the entire capture period of the target insect (which could last from a few days to several months). ${ }^{4,5}$ The search for adequate materials to be used as pheromone dispensers for several kinds of pheromone molecules is a challenge in this field. Many kinds of materials have been investigated as pheromone dispensers, such as filter paper, ${ }^{6}$ nylon mesh, ${ }^{7}$ polymers, ${ }^{8,9}$ paraffin wax, ${ }^{10}$ zeolites $^{4}$ and glass ampoules, ${ }^{11}$ among others. The commercially available dispensers are mainly made from different kinds of polymers.

As insightfully pointed out by Muñoz-Pallares et $a l .{ }^{4}$ there are four basic requirements for an effective pheromone dispenser: (i) kinetic emission should be close to the optimum velocity for each specific capture (which depends on several characteristics as intensity and type of pest, weather conditions, type of treatment being employed, etc.), in order to decrease the number of applications required; (ii) the dispenser should adapt to various release requirements (chemical characteristics of pheromone molecules, type of treatment, weather conditions); (iii) since a great number of insect pheromones are composed of a mixture of compounds (generally containing different volatilities), dispensers should be able to adsorb and further emit these components at the correct proportions; (iv) dispensers should be environmentally inert.

Silica-based porous glasses theoretically have all the characteristics listed above. Among several kinds of silicabased porous glasses, the so-called porous Vycor glass (PVG) is a commercial (Corning 7930) transparent porous material obtained by acid leaching of a phase-separated alkaline borosilicate glass. The soluble borate phase is dissolved, leaving an open porous structure of essentially pure silica with interconnecting pores, a narrow pore size distribution (between 2 and $20 \mathrm{~nm}$ ) and a pore volume of nearly $28 \%$. The pore surface contains slightly acidic silanol groups ( $\left.\mathrm{pK}_{\mathrm{a}} c a .9\right) .{ }^{12,13}$ The nanometric pores in PVG have been used to incorporate several compounds (conducting polymers, ${ }^{14-16}$ oxides,,${ }^{17-19}$ semiconductors, ${ }^{20}$ amorphous carbon, ${ }^{21}$ and carbon nanotubes ${ }^{22}$ ), with the purpose of obtaining novel functional nanocomposite materials.

The objective of this work was to demonstrate the feasibility of using PVG as a pheromone dispenser, and, to do so, PVG was impregnated with different pheromones. The assays included the characterization of the impregnated-PVG, the study of the pheromone release ratios under laboratory conditions and the practical application in two different cropping areas. To the best of our knowledge, this is the first report on the use of porous glasses as insect pheromones dispensers.

\section{Experimental}

1-Dodecanol was purchased from Aldrich and the synthesis of the corresponding dodecyl acetate was carried out by reaction with acetic anhydride and pyridine..$^{23}$ 5,9-Dimethylpentadecane was supplied from Fuji Flavor (Japan) or synthesized as previously reported. ${ }^{24}(Z)-8$ Dodecenyl acetate (Z8-12Ac), (E)-8-dodecenyl acetate ( $E 8$ 12Ac) and (Z)-8-dodecen-1-ol (Z8-12OH) were supplied from ShinEtsu (Japan) and were used as received. The PVG plates (Corning 7930) were cut into $10 \times 10 \times 1 \mathrm{~mm}$ pieces, and treated in order to remove impurities adsorbed in their pores. The plates were immersed in a $2 \mathrm{~mol} \mathrm{~L}^{-1} \mathrm{HCl}$ solution for $30 \mathrm{~min}$, washed with deionized water, dried, immersed in acetone for $30 \mathrm{~min}$, dried, left at $550{ }^{\circ} \mathrm{C}$ for $72 \mathrm{~h}$, cooled to room temperature and stored in desiccator prior to use. The rubber septa dispensers were purchased from Aldrich.

The impregnation of pheromones into PVG was done as follows: a suitable amount of pheromone (to be impregnated into one PVG plate) was dissolved in $5.0 \mathrm{~mL}$ of solvent (hexane), and one PVG plate was placed inside the pheromone solution. The system was kept at room temperature until complete solvent evaporation. After that, the PVG plate was ready for use. For comparison purposes, the same incorporation procedure was employed using commercial rubber septum $(8 \mathrm{~mm}$ OD, white rubber, Aldrich). It is important to note that this procedure is widely used to impregnate pheromones into rubber septa, and was adapted simply by replacing the septum by the PVG plate. The amount of pheromone per PVG plate (or rubber septum) was $2.5 \mathrm{mg}$ for 1-dodecanol, dodecylacetate and 5,9-dimethylpentadecane. For the G. molesta pheromone mixture, the amounts of Z8-12Ac, E8-12Ac and Z8-12OH were $279 \mu \mathrm{g}, 18 \mu \mathrm{g}$ and $3 \mu \mathrm{g}$ (ratio 93/6/1), respectively, for each PVG plate (or rubber septum).

The pheromone-incorporated PVG plates and rubber septa were placed in different all-glass aeration chambers, at $26 \pm 2^{\circ} \mathrm{C}$, and the volatiles released were trapped in Super $\mathrm{Q}$ (Alltech, Deerfield, Illinois, USA) columns for 24 hours. A humidified charcoal-filtered airstream $\left(1 \mathrm{~L} \mathrm{~min}^{-1}\right)$ was maintained through the aeration apparatus. The columns were washed with bidistilled hexane, and the extracts were concentrated to $100 \mu \mathrm{L}$, under argon stream, in a clean conical bottom vial. ${ }^{25}$

Gas chromatographic analyses were performed on a Varian 3800 GC equipped with FID, electronic pressure 
control, and operated in the splitless mode. A DB-5 $(30 \mathrm{~mm} \times 0.25 \mathrm{~mm} \times 0.25 \mu \mathrm{m})$ capillary column was used under the following analytical conditions: initial temperature of $70{ }^{\circ} \mathrm{C}$ for $1 \mathrm{~min}$, with an increase of $7{ }^{\circ} \mathrm{C}$ $\min ^{-1}$ until a final temperature of $250{ }^{\circ} \mathrm{C}$, which was maintained for $10 \mathrm{~min}$. Upon finishing, the chromatograms were analyzed and compared with one another to detect pheromone release rate differences.

Mass spectra were recorded on a Shimadzu QP 5050A GC/MS quadrupole detector using the same type DB-5 capillary column and under the same conditions described above. The equipment was operated in the electron impact (EI) ionization mode $(70 \mathrm{eV})$. The amount of pheromone in the samples was calculated based on an external standard curve.

The FT-IR spectra for the samples were obtained with a Bio-Rad Excalibur FTS 3500GX spectrophotometer in the 4000 to $400 \mathrm{~cm}^{-1}$ range, with 32 scans. DRIFT spectra were obtained with the same spectrophotometer, using a Spectratec Gemini accessory.

The field tests for both insect species followed the same procedure, described as follows: monitoring traps containing both types of dispensers (PVG or rubber septum) were placed either in coffee or apple areas and checked regularly to count the number of males caught in each trap. Field experiments for $L$. coffeella were run in coffee plantations in Viçosa-MG, Brazil. PVG and rubber septa were loaded with synthetic 5,9-dimethylpentadecane and delta traps (10 per treatment) were positioned randomly $30 \mathrm{~m}$ apart from one another in the field. Traps were placed at $0.1 \mathrm{~m}$ above the ground. Moths trapped were counted every week, during seven weeks. The insects were removed after each count. The lures were placed at the bottom of the traps.

Trap tests for G. molesta were conducted in an orchard at Embrapa, Vacaria-RS, Brazil, from November, 2005 to April, 2006. The sex pheromone of this insect is composed mainly of three different compounds, Z8-12Ac, E8-12Ac and $\mathrm{Z8}-12 \mathrm{OH},{ }^{24}$ in the following proportion $(\mathrm{m} / \mathrm{m}): 93 / 6 / 1$. Tetra traps were baited with pheromone-impregnated rubber septa or PVG plates and placed in the orchard. The traps (10 for each treatment) were placed at a height of ca. $1.7 \mathrm{~m}$ in apple trees. Traps were $8 \mathrm{~m}$ apart from one another, and were arranged in random order on a line along tree rows. Replicates were placed in different tree rows at a $20 \mathrm{~m}$ distance from one another. Traps were inspected once a week.

\section{Results and Discussion}

The first attempts to verify whether the purpose was feasible were conducted by incorporating three different pheromone molecules into both PVG and commercial septa: 1-dodecanol and dodecyl acetate, sex pheromones of several Lepidoptera species, and 5,9-dimethylpentadecane, the sex pheromone of $L$. coffeella, an important pest of coffee plantations in Brazil. Dodecanol and dodecyl acetate were selected in order to make comparisons between two pheromones containing similar chemical structures but different functional groups. 5,9-Dimethylpentadecane was selected to verify the behavior of an alkane (as compared to alcohol and acetate) and to conduct a practical test in a crop.

When the porous glass plate is introduced into the pheromone solution, diffusion of the pheromone and solvent molecules to the interior of the glass pores occurs through a capillarity process, as reported earlier for the incorporation of different neutral molecules into PVG. ${ }^{18,22}$ The capillarity of the pheromone molecules is enhanced during evaporation of the highly volatile solvent. These facts, added to the small amount of pheromone employed in each incorporation procedure, make us consider that almost all the initial pheromone was impregnated into PVG after complete evaporation of the solvent. However, some pheromone molecules losses cannot be discarded (due to evaporation or to some molecules that were left on the walls of the glass flask where impregnation was carried out). The co-impregnated solvent is naturally eliminated by evaporation.

In order to verify the presence of pheromone molecules incorporated into PVG, the samples were characterized by infrared spectroscopy. Due to the low concentration of the incorporated compounds, the FTIR spectra of the samples in conventional $\mathrm{KBr}$ disks or mineral oil dispersion are strongly dominated by the spectrum of the pristine glass. Although this effect is also observed when the spectra are obtained in diffuse reflectance mode (DRIFT), it is less evidenced and some information can be collected. Figure 1 shows the DRIFT spectra of the impregnated PVG samples. The DRIFT spectrum for pristine PVG and the transmission mode FTIR spectra for the neat pheromones are also shown for comparison.

The spectra presented in Figure 1 clearly show that the pheromone molecules were successfully impregnated after all procedures. The $\mathrm{C}-\mathrm{H}$ stretching bands in the 2800$3100 \mathrm{~cm}^{-1}$ region, common to all studied pheromones, are observed in the spectra of the three impregnated samples. Also, the carbonyl band at $1745 \mathrm{~cm}^{-1}$, typical of ester compounds, should be clearly detected in the ester-impregnated PVG plate (indicated with an asterisk in Figure 1d).

The DRIFT spectra presented in Figure 1 also provided indirect information about the interactions between PVG 


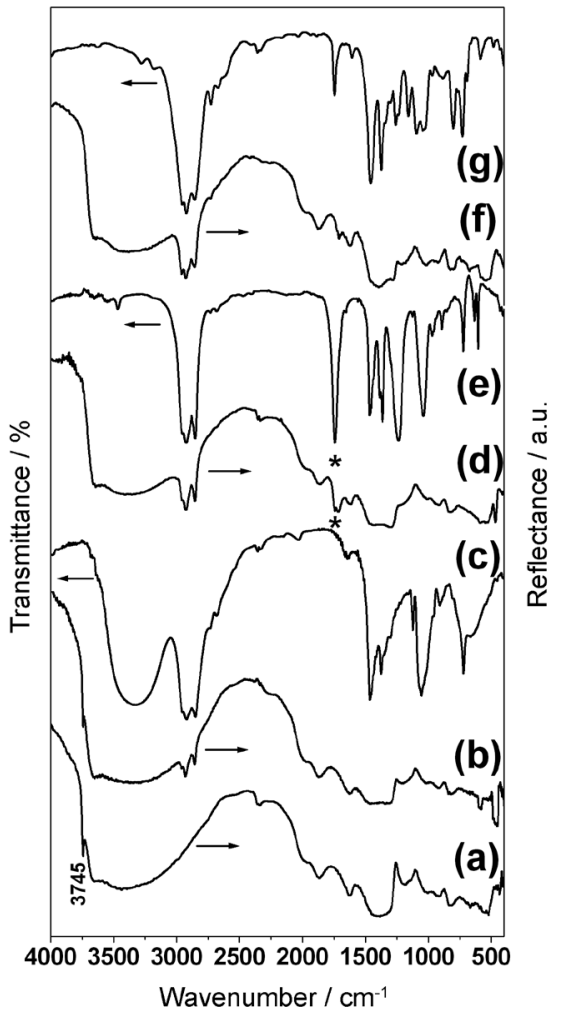

Figure 1. Infrared spectra in transmittance (c,e,g) and diffuse reflectance (a,b,d,f) modes: (a) pristine PVG; (b) PVG impregnated with 1-dodecanol; (c) neat 1-dodecanol; (d) PVG impregnated with dodecyl acetate; (e) neat dodecyl acetate; (f) PVG impregnated with 5,9-dimethylpentadecane; (g) neat 5,9-dimethylpentadecane.

and the incorporated pheromones. The pristine PVG spectrum (Figure 1a) shows a sharp band at $3745 \mathrm{~cm}^{-1}$ attributed to the free $\mathrm{O}-\mathrm{H}$ stretching of surface silanol groups. ${ }^{26}$ When the dodecyl acetate and the alkane were impregnated into PVG, this band disappeared (Figure 1d and 1f), indicating the occurrence of van der Walls-like chemical interactions between these molecules and the silanol groups from the PVG surface. This effect was not fully observed in the spectrum of the alcohol-incorporated PVG (Figure 1b). In this case the relative intensity of the $3745 \mathrm{~cm}^{-1}$ band decreased (as compared to the pristine PVG), but the band did not disappear, indicating a poor chemical interaction between the alcohol molecules and the silanol groups from the PVG pore surface. This is an unexpected result, because an alcohol is supposed to have strong chemical interactions with silanol groups. However, this experimental observation is absolutely reproducible and is reflected on the emission behavior of the alcohol impregnated into PVG, as will be discussed on the following paragraphs. A possible explanation for this occurrence is that the alcohol molecules in solution should be organized in molecular associations (like micelles), and these molecular aggregates are the real entities impregnated into PVG. However, further studies are necessary to clarify this point.

The emission behavior of each type of pheromone molecule incorporated into PVG and into rubber septum is presented in Figure 2. A careful analysis of this emission data indicates the following: (i) the pheromones
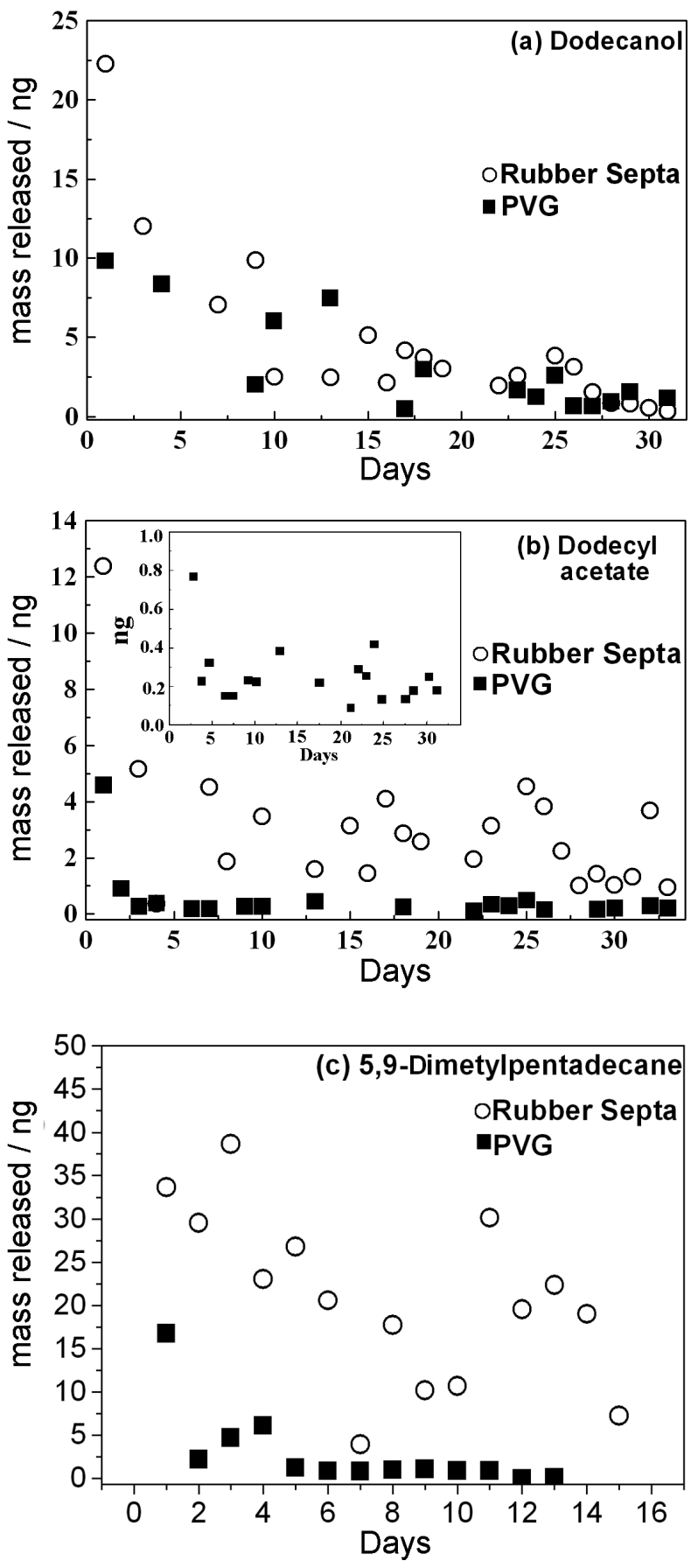

Figure 2. Release ratio for the pheromone molecules impregnated into PVG plates (squares) and rubber septa (open circles): (a) 1-dodecanol; (b) dodecyl acetate; (c) 5,9-dimethylpentadecane. The inset in (b) corresponds to a zoom of the data for PVG-impregnated molecules, in order to better distinguish the lower (close to zero) emission rates. 
impregnated into PVG are continuously released during the 30 days in which the emission was monitored; (ii) comparing the release behavior of PVG and rubber septa, PVG release is steadier, while rubber septa releases had large fluctuations; (iii) the 1-dodecanol release behavior for PVG and rubber septa is very similar, while those of dodecyl acetate and 5,9-dimethylpentadecane are significantly different. In the case of the latter, the amount of pheromone released from PVG is very small (although significantly steady) as compared to that from the rubber septum and to the amount of 1-dodecanol released from PVG itself. This fact is the result of the kind of interactions between the pheromone molecules and the PVG pores surface. As detected by DRIFT, apparently the ester and alkane molecules are more strongly bonded to the surface of PVG pores than the alcohol, and this causes slower ester and alkane releases when compared with the alcohol.

Once the PVG ability to incorporate and control the release of pheromone molecules was demonstrated, it was necessary to verify whether it could be employed as a dispenser in a real application. Figure 3 shows L. coffeella male capture results from ten different traps for each dispenser (PVG and rubber septa), monitored during seven weeks. The same amount of pheromone was impregnated into each dispenser $(2.5 \mathrm{mg}$ per $\mathrm{PVG}$ plate or rubber septum). A single dispenser was placed inside each trap, and traps were randomly arranged at different positions within the coffee plantation. It can be noted from Figure 3 that insect captures in traps containing the PVG dispenser were almost the same as captures in traps containing the commercial rubber septa. A significant number of males were captured in each trap. Despite weather changes (humidity, wind direction and velocity, temperature),

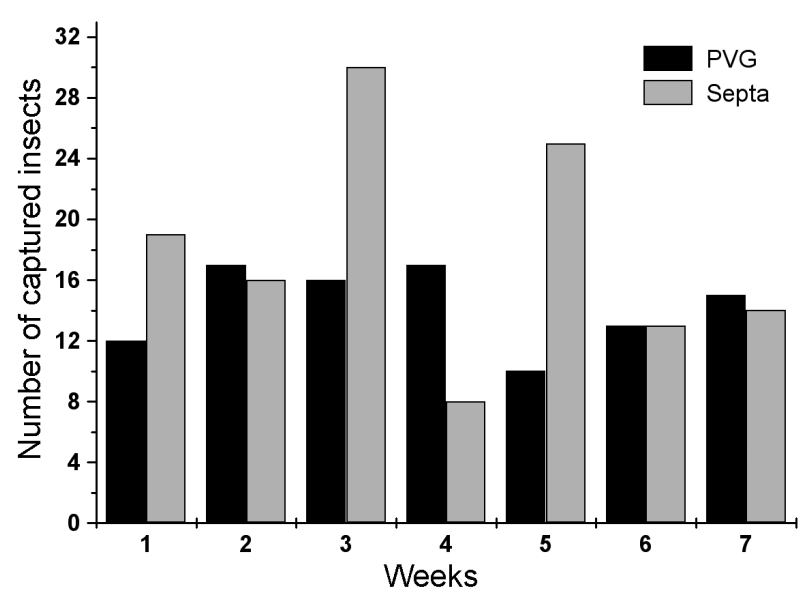

Figure 3. Number of insects (L. coffeela) captured in a coffee plantation over seven weeks, in traps containing the pheromone molecules impregnated into PVG or into rubber septa. captures were relatively constant over the seven weeks during which the traps were monitored.

Finally, PVG and rubber septa were impregnated with a mixture of G. molesta pheromone compounds. The sex pheromone of this insect is composed mainly of three different compounds, Z8-12Ac, E8-12Ac and Z8-12OH, ${ }^{24}$ in the following proportion $(\mathrm{m} / \mathrm{m}): 93 / 6 / 1$. This proportion was rigorously maintained during the incorporation process. Effective impregnation was also monitored by DRIFT (data not shown). The emission behavior study of both PVG and rubber septum impregnated with the mixture of compounds indicated that the three components are continuously released during the 35 days in which the experiment was carried out. The most exciting result, however, was obtained for the emission ratio, shown in Figure 4. The average proportion of $(Z 8-12 \mathrm{Ac}) /(E 8$ $12 \mathrm{Ac}) /(\mathrm{Z} 8-12 \mathrm{OH})$ released by the PVG during 35 days was $96.4 / 3.4 / 0.2$, which is close to the ideal proportion and equivalent to the average proportion released by the rubber septum (95.7/4.0/0.3).

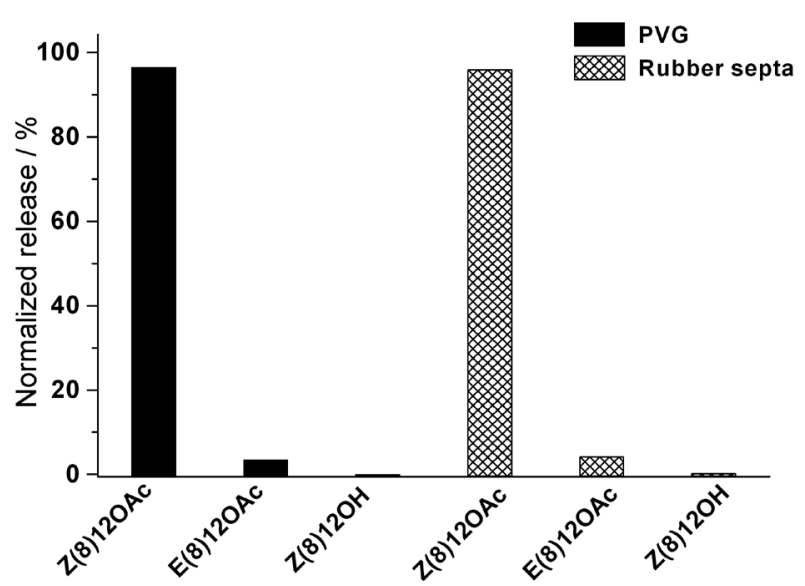

Figure 4. Release ratio for the pheromone molecules impregnated into PVG and rubber septa: (Z)-8-dodecenyl acetate (Z8-12Ac); (E)-8dodecenyl acetate (E8-12Ac); (Z)-8-dodecen-1-ol (Z8-12OH).

Figure 5 shows male insect capture results of ten different traps for each dispenser (PVG and rubber septa), in an apple orchard, monitored over a six-week period.

The PVG and rubber septa produced different capture patterns. Insect captures with PVG were higher in the initial weeks, while capture with rubber septa was higher at the final weeks. This could mean that the pheromone releases in the apple orchard were different according to type of dispenser. However, a similar number of males were caught with each type of dispenser, which definitively confirms the high potential of PVG in the field. The higher number of males caught in weeks 2 and 4 occurred due to G. molesta adult population fluctuations in the orchard. This was confirmed when comparing our data with data from other 


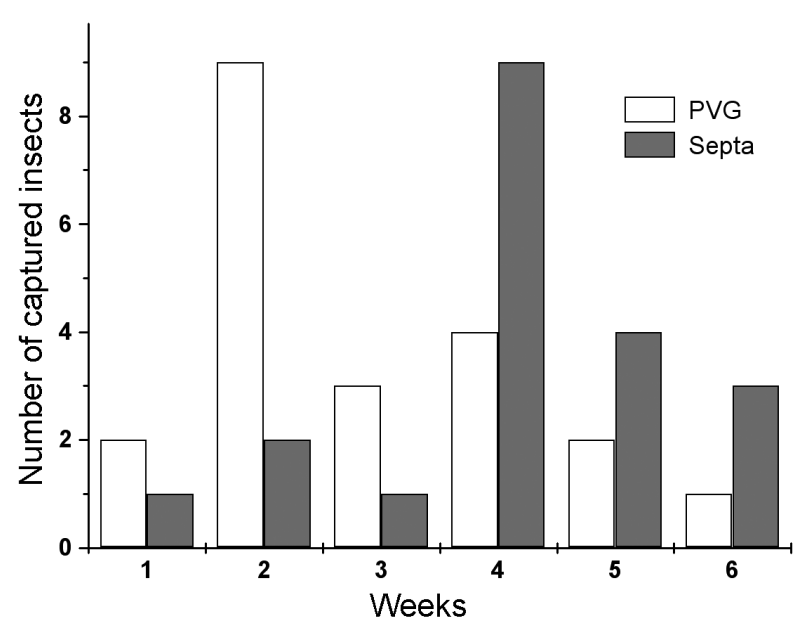

Figure 5. Number of insects (G. molesta) captured in an apple orchard over seven weeks, in traps containing the pheromone molecules impregnated into PVG or into rubber septa.

monitoring traps placed in adjacent apple orchards, since the apple fruit growers have to apply pheromone traps to detect this insect and decide when to apply the chemical control.

An extra advantage of PVG over other materials usually employed as pheromone dispensers is the possibility of reuse during a number of cycles. We conducted several experiments and demonstrated that once the impregnated pheromone was completely delivered, the PVG monolith can be incorporated again, with release kinetics remaining almost unchanged (data not shown). These impregnation/ release/impregnation cycles are likely to be repeated several times with no damage to the quality of the material. Another important point is the possibility to control the amount of pheromone to be impregnated in each PVG plate. The data presented here for the alkane and ester impregnation was based on $2.5 \mathrm{mg}$ of pheromone per $\mathrm{PVG}$ plate. We had performed experiments starting from $25.0 \mathrm{mg}$ of pheromone, and observed that the impregnation was also effective. Also, the preliminary results regarding the pheromone emission indicate that the amount of pheromone released increases with the increase of the amount of pheromone previously impregnated. These results can be very important to optimize the release ratios for different pheromones in different crop areas.

\section{Conclusions}

This work demonstrates for the first time the possibility of using a porous silica glass as insect pheromone dispenser. The impregnation step, characterization of the impregnated material, study of the emission dynamics and practical tests in two different crops were carried out, and the results show that the porous Vycor glass has an equivalent performance when compared to the commercial materials currently used as dispensers. The main advantages of using PVG were the potential for better steadiness during emission, the easiness in which pheromone molecules can be impregnated (using the same procedure widely employed for impregnation of commercial rubber septa), the possibility to control the amount of pheromone to be incorporated and released, the possibility of reuse for several impregnation/release cycles and the environmentally-friendly aspect of PVG. We believe that the results obtained in this work can probably be extended to other types of pheromone molecules, as well as to other porous glasses (as for example porous glasses obtained via the sol-gel route). Efforts towards these directions are currently under investigation in our laboratory.

\section{Acknowledgments}

Authors acknowledge the Funding Agencies CNPq, CAPES/PROCAD, T. W. A. S. and I. F. S. for the support. A.T. thanks CAPES for a fellowship.

\section{References}

1. Dicke, M.; Sabelis, M. W.; Takabayashi, J.; Posthumus, M. A.; J. Chem. Ecol. 1990, 16, 3091.

2. Tomaszewska, E.; Herbert, V. R.; Brunner, J. F.; Jones, V.; Doerr, M.; Hilton, R.; J. Agric. Food Chem. 2005, 53, 2399.

3. Cox, P. D.; J. Stor. Prod. Res. 2004, 40, 1.

4. Muñoz-Pallares, J.; Corma, A.; Primo-Yufera, J.; J. Agric. Food Res. 2001, 49, 4801.

5. Donough, M. C.; J. Chem. Ecol. 1997, 23, 1211.

6. Beroza, M.; Bierl, B. A.; Knipling, E. F.; Tardif, J. G. R.; J. Econ. Entomol. 1971, 64, 1527.

7. Shorey, H. H.; Kaae, R. S.; Gaston, L. K. ; McLaughlin, J. R.; Environ. Entomol. 1972, 1, 641.

8. Hendricks, D. E.; Environ. Entomol. 1995, 12, 85.

9. Bradley, S. J.; Suckling, D. M.; McNaughton, K. G.; Wearing, C. H.; Karg, G. A.; J. Chem. Ecol. 1995, 21, 745.

10. Atterholt, C. A.; Delwiche, M. J.; Rice, R. E.; Krochta, J. M.; J. Control. Release 1999, 57, 233.

11. Hofmeyr, J. H.; Burger, B. V.; J. Chem. Ecol. 1995, 21, 355.

12. Wiltzius, P.; Bates, F. S.; Drieker, S. B.; Phys. Rev. A: At., Mol., Opt. Phys. 1987, 36, 2991.

13. Gafney, H. D.; Coord. Chem. Rev. 1990, 104, 113.

14. Zarbin, A. J. G.; De Paoli, M-A.; Alves, O. L. Synth. Met. 1999, 99, 227.

15. Zarbin, A. J. G.; De Paoli, M-A.; Alves, O. L.; Synth. Met. 1997, 84, 107

16. Maia, D. J.; Zarbin, A. J. G.; Alves, O. L.; De Paoli, M-A.; Adv. Mater. 1995, 7, 792. 
17 Menezes, W. G.; Camargo, P. H. C.; Oliveira, M. M.; Evans, D. J.; Soares, J. F.; Zarbin, A. J. G.; J. Colloid Interface Sci. 2006, 299, 291.

18. Zarbin, A. J. G.; Vargas, M. D.; Alves, O. L.; J. Mater. Chem. 1999, 9, 519.

19. Mazali, I. O.; Souza Filho, A. G.; Viana, B. C.; Mendes Filho, J.; Alves, O. L.; J. Nanopart. Res. 2006, 8, 141.

20. Romano, R.; Alves, O. L.; Mater. Res. Bull. 2006, 41, 376.

21. Zarbin, A. J. G.; Bertholdo, R.; Oliveira, M. A. F. C.; Carbon 2002, 40, 2413.

22. Schnitzler, M. C.; Mangrich, A. S.; Ardisson, J. D.; Macedo, W. A. A.; Zarbin, A. J. G.; Inorg. Chem. 2006, 45, 10642.
23. Huang, Y.; Shi, L.; Yang, J.; J. Org. Chem. 1987, 52, 3558.

24. Zarbin, P. H. G.; Princival, J. L.; Lima, E. R.; Santos, A. A.; Ambrogio, B. G.; Oliveira, A. R. M.; Tetrahedron Lett. 2004, 45, 239.

25. Zarbin, P. H. G.; Ferreira, J. T. B.; Leal, W. S.; Quim. Nova 1999, 22, 263.

26. Law, M. J. D.; Ramasubramanian, N.; J. Phys. Chem. 1966, 70, 2740.

27. Cardé, A. M.; Baker, T. C.; Cardé, R. T.; J. Chem. Ecol. 1979, 5, 423.
Received: December 12, 2007 Web Release Date: October 15, 2008 